
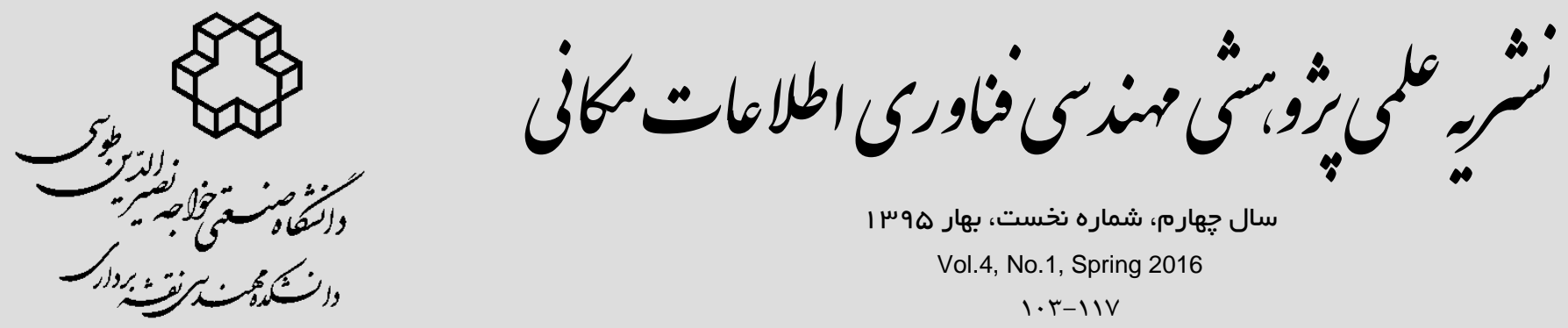

سال جهارم، شماره نخست، بهار هوس

Vol.4, No.1, Spring 2016

$1 \cdot r-11 V$

كاليبراسيون قطب نماى جريان سنج دريايى با استفاده ازتعيين موقعيت كينماتيك نسبى

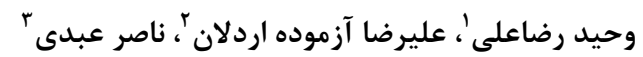

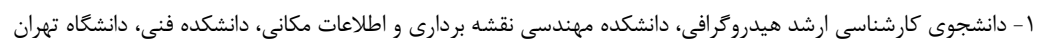

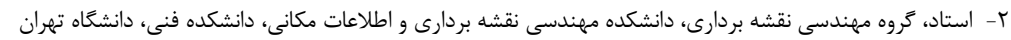

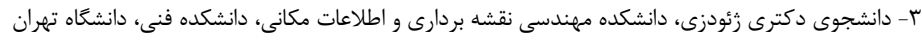

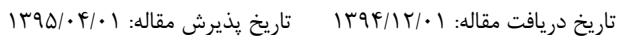

جكيده

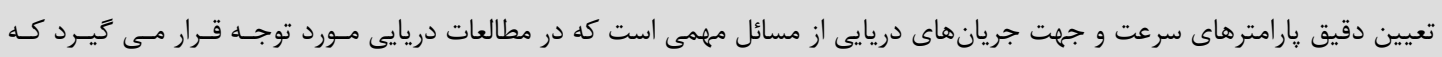

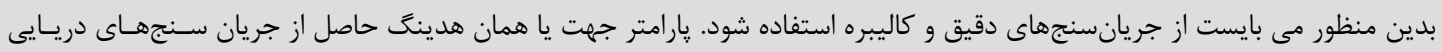

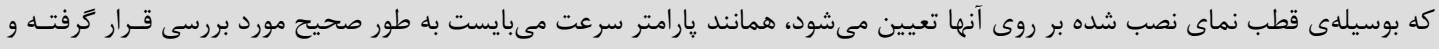

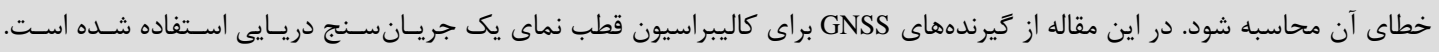

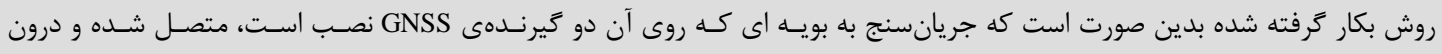

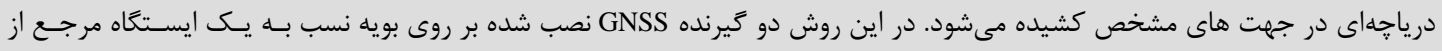

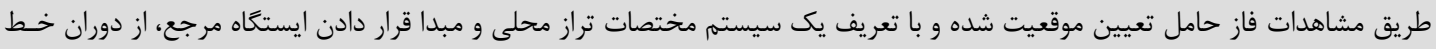

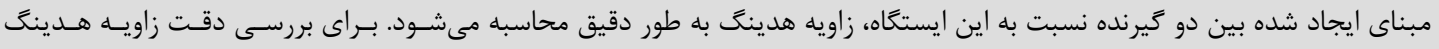

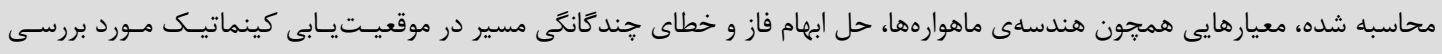

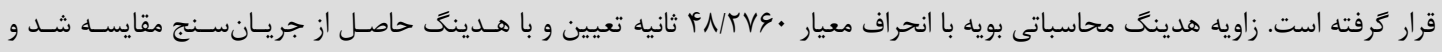

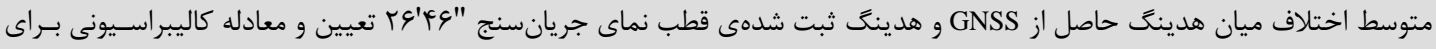
قطب نماى مغناطيسى جريانسنج دريايى ارائه شد.

كليدوازهها: زاويه هدينك، GNSS، كينماتيك نسبى، جريانسنج دريايى، كاليبراسيون جريانسنج

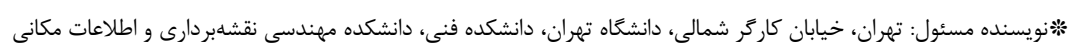

Email: geo1.vra@gmail.com

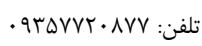


استفاده شده است. روش مورد نظر بدين صـورت اسـت كه جريانسنج به بويهاى مجهز به دو كيرنسدى

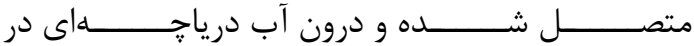
جهتهاى مشخص كشيده مىشود و هدينَ حاصـل از جريانسنج با هدينگ دقيـق محاسـبه شـده از مقايسه مسىشـود. در ايـن روش دو كَيرنـده بــه عنــوان

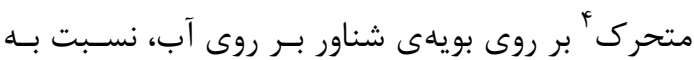
كيرندهاى ثابت و مستقر در خارج از آب تعيين موقعيت

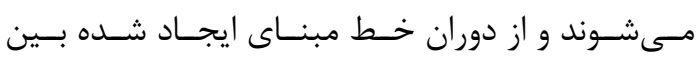

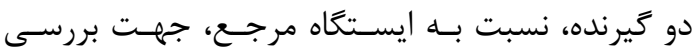

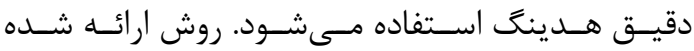

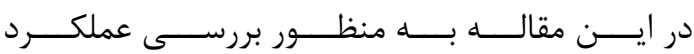
جريانسنج دريايى از نوع بروانهاى، روشى ابتكارى بوده

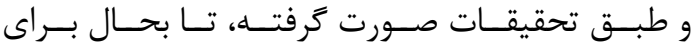
بررسى ميدانى عملكرد اين جريانســنج مـورد اسـتفاده قرار نكرفته است. اما استفاده از روش تعيين يار امترهاى

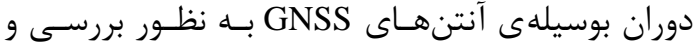

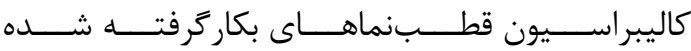
در محيطهاى دريايى روشى شـناخته شـده مسىباشـد.

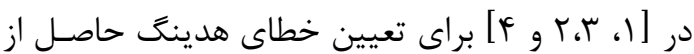
قطـبنمـاى زيرسـكويى كـهـ تـاثير بسـزايى در تعيـين

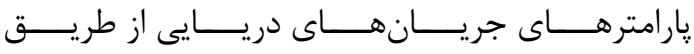

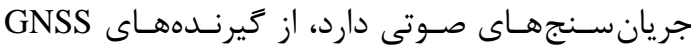

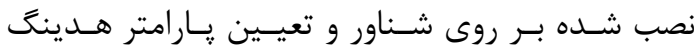

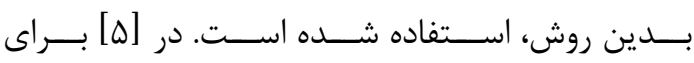
كاليبراسيون سنسور جهت يابى مغناطيسى از دو كيرنده

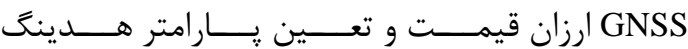

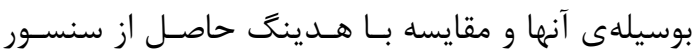
مورد نظر استفاده شده اسـت. در [ع] از طريـق تعيـين

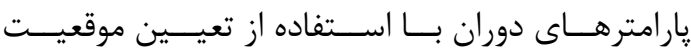
كينماتيك آنى كيرندههاى GNSS بـراى كالي داليبراسـيون يك قطبنماى مغناطيسى استفاده شده است.

${ }^{4}$ Rover

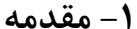

كسب اطلاعات صحيح از يارامترهاى جريانهاى دريايى

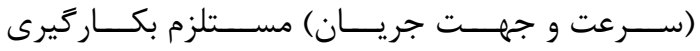

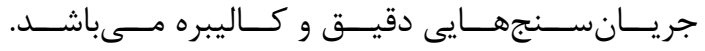
جريـانسـنجهــاى دريـايى انـواع كونـاكونى را شـامل

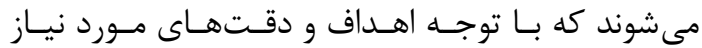
در مطالعات و يروزههاى دريايى به كار گرفته مىشـوند.

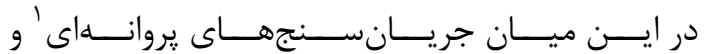

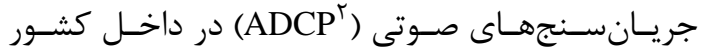

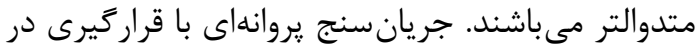

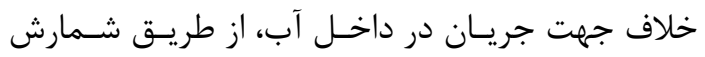
تعداد دور در ثانيه توسط خرخش يروانهى خود ميـزان

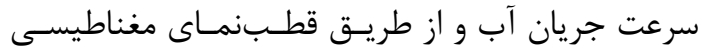

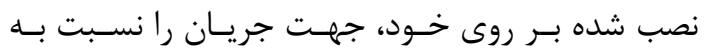
شمال مغناطيسى تعيين مى كند. اما بـراى اطمينـان از

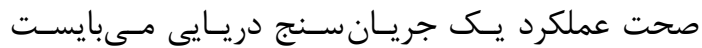

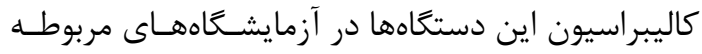

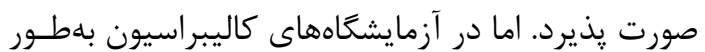
معمول سنسور سرعتيابى جريانسنجها مـورد بررسى

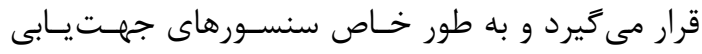

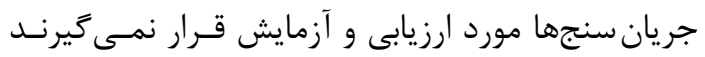

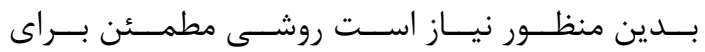
ارزيابى سنسور جهتيابى جريانسنج ارائه شود تا بتوان

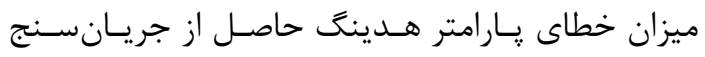
را تعيين كرد.

براى بررسى عملكرد جهت يابى جريانسنجهاى دريـايى

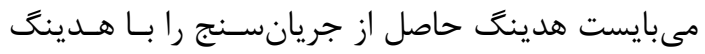

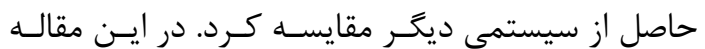

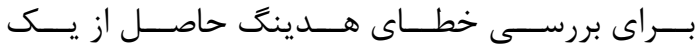

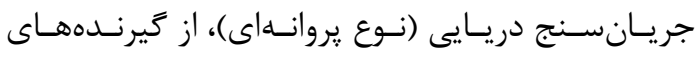

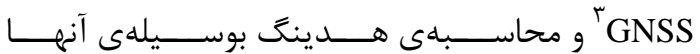

\footnotetext{
${ }^{1}$ Impeller current meter

${ }^{2}$ Acoustic Doppler Current Profiler

${ }^{3}$ Global Navigation Satellite System
} 


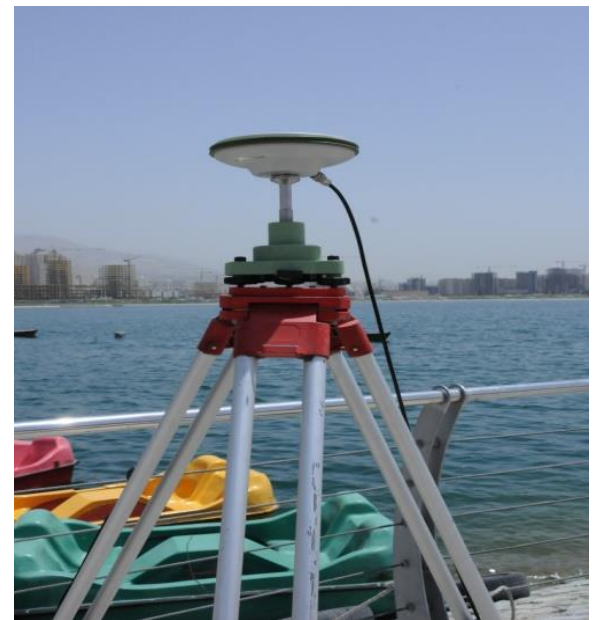

شكل ؟ : كيرندهى مستقر در خارج از درياجه به عنوان

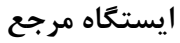

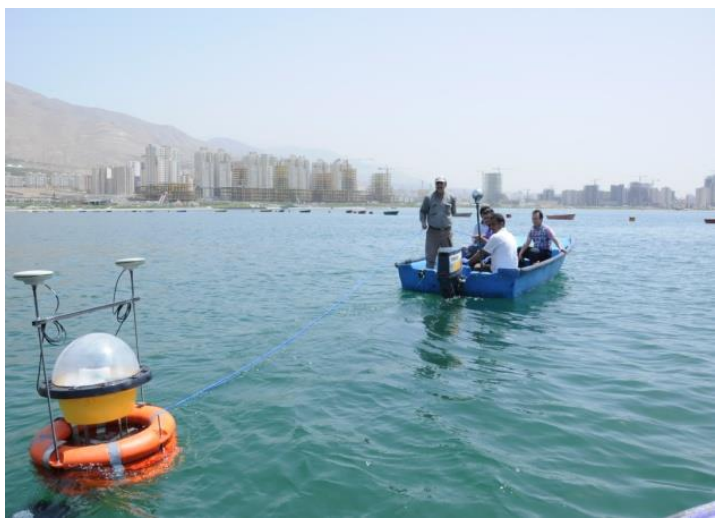

شكل ץ : برداشت دادههاى ميدانى

جريـانســنج دريـايى مــورد اسـتفاده در ايـن تحقيـق

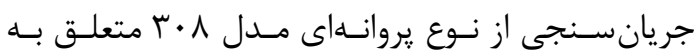

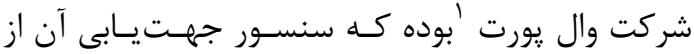

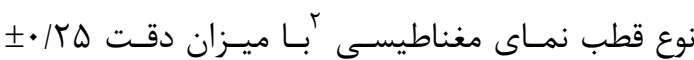

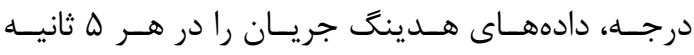

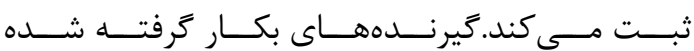
در اين عمليات، كَيرنـدهـــاى دو فر كانسـهـ لايكـا مـدل

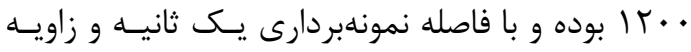

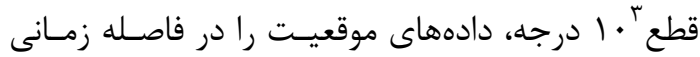

r- عمليات ميدانى و برداشت دادهها به منظور آزمايش روش مورد نظر بويهاى طراحسى شــد

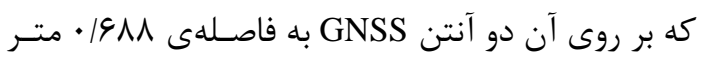

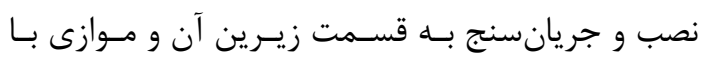
خط مبناى ميان دو گيرنده، متصـل شـد (شـكل (1) (). براى به آب اندازى بويه و קيادهسازى روش مـورد نظـر،

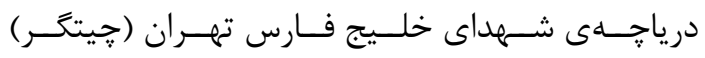

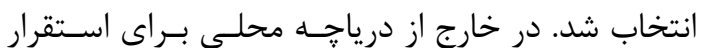

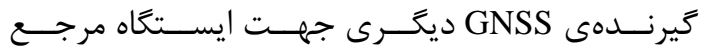

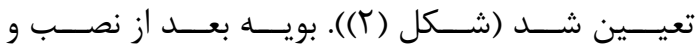
جاسازى گيرنسدهــاى GNSS بــهـ درون آب انداختـهـ و بوسيلهى طنابى از طريق قايقى بر روى آب درياجـهـ در جهتهايى مشخص، كشيده شد.

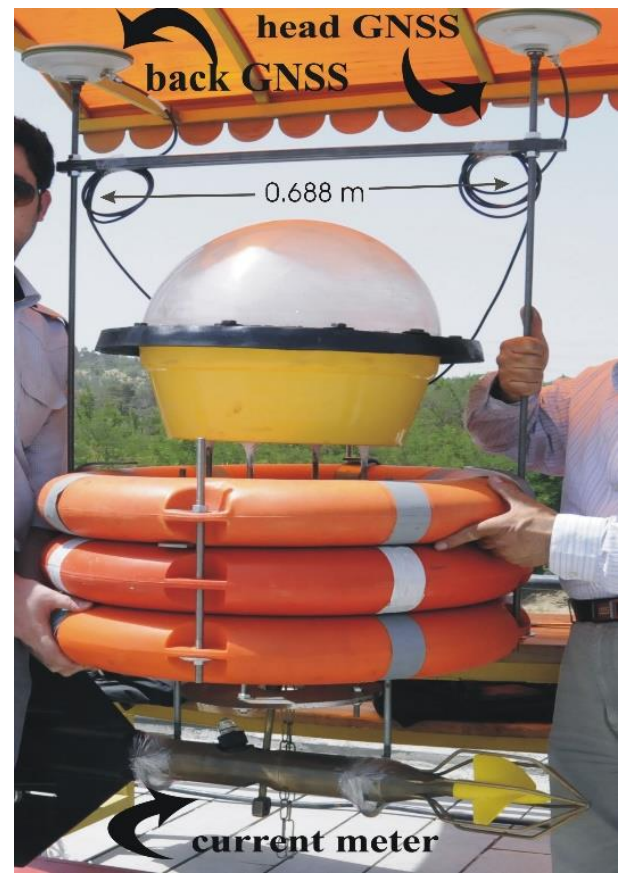

شكل I : بويه به همراه كيرندههاى GNSS و جريانسنج

\footnotetext{
${ }^{1}$ Valeport

${ }^{2}$ Flux gate compass

${ }^{3}$ Cut off angle
} 


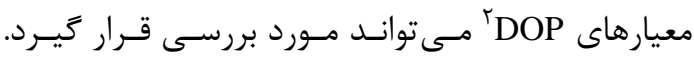
در شكلهاى (ووه) صورت فلكى بحاصل از ماهوارههاى

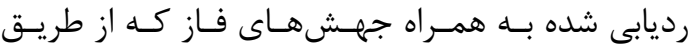

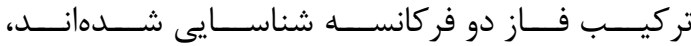

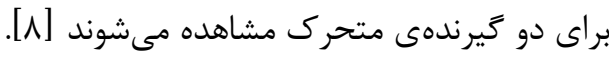

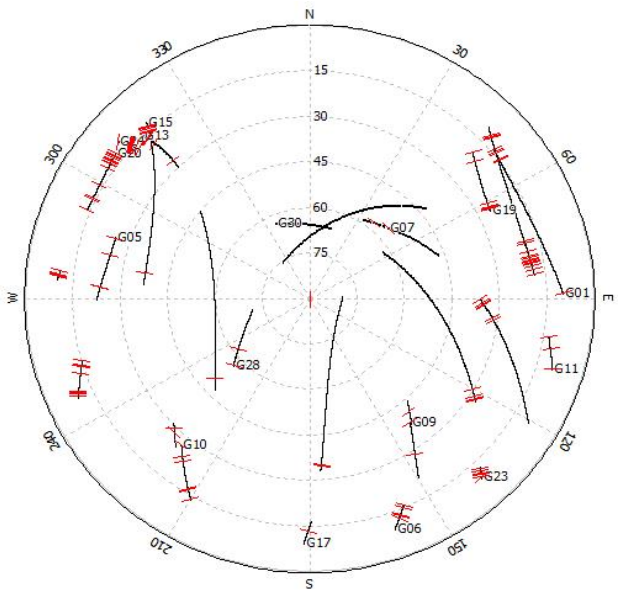

شكل ه : صورت فلكى گَيرنده عقب به همراه نمايش جهشهاى فاز (خطوط قرمز رنَ)

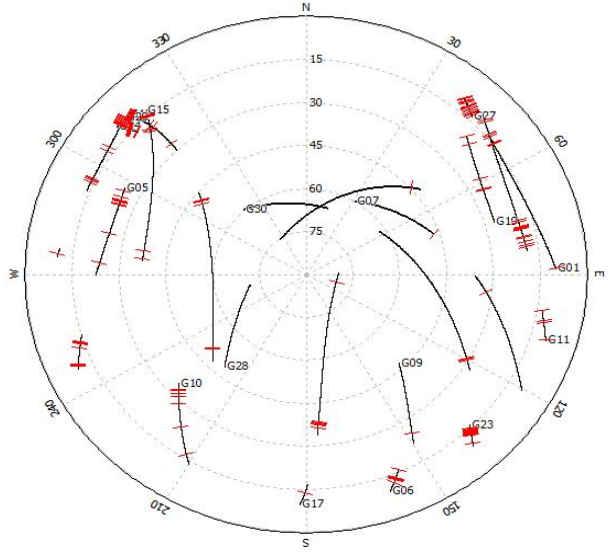

شكل 9 : صورت فلكى تَيرنده جلو به همراه نمايش

جهشهاى فاز (خطوط قرمز رنَ)
تقريبا ه/1/ سـاعت برداشـت كردنـد. مطـابق شـكل (I) كيرندهى نصب شده در جلوى مسير حركت، بـهـعـــان

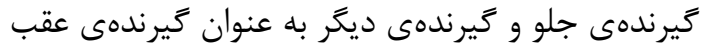
در نظر گرفته شده است.

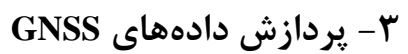

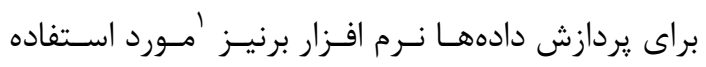

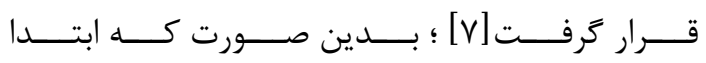
موقعيت ايستكاه مرجع به روش تعيين موقعيت نقطهاى

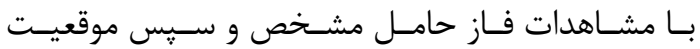

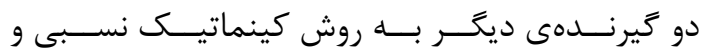

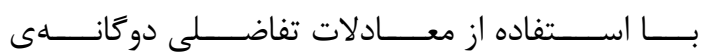

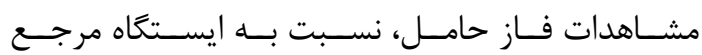
تعيين شدند. (شكل (\&))

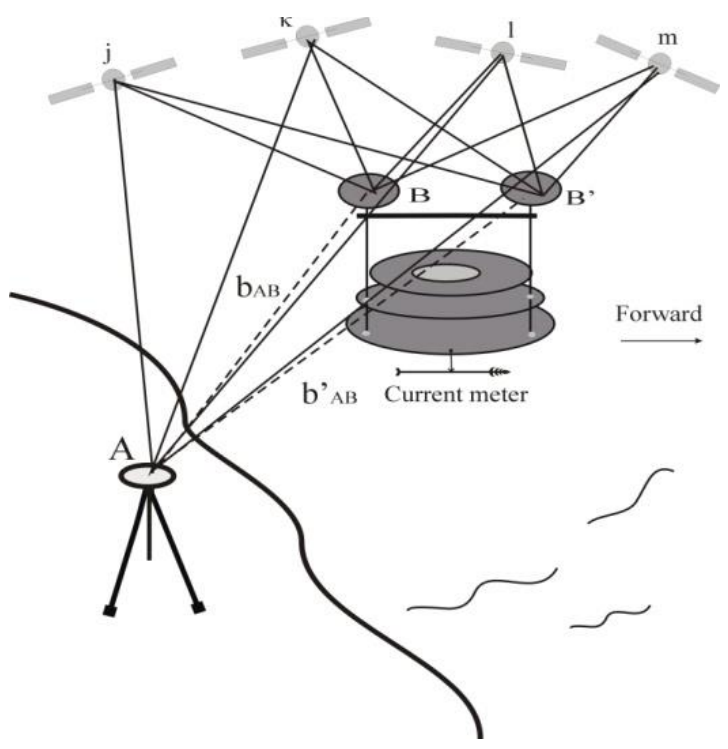

شكل f : اساس تعيين موقعيت كينماتيك نسبى براى

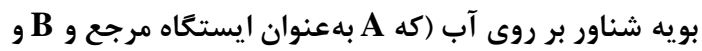

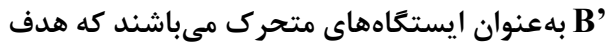
در تعين موقعيت كينماتيك نسبى تعيين دو بردار خط مبنا b'

براى بررسى دقت و صحت حاصل از موقعيتيابى نقاط،

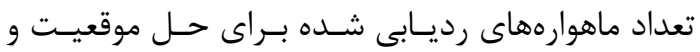

${ }^{1}$ Bernese 5.0 software 
به طور صحيح حل شده و در تمـام زمـان ثابـت باشـند

به محض آن كه مقدار ابهام به صورت عدد صحيح معلوم شود كفته مىشود كه ابهام رفع شده يا و وند

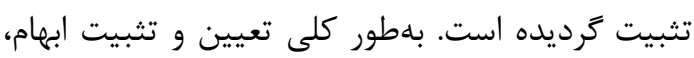
حل خط مبنا را استحكام مىبخشد [11]. استفاده از تفاضلهاى دوكانه به جاى تفاضلهاى يكانه،

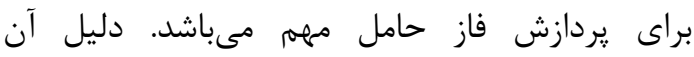
اين است كه در مورد تفاضلهاى يكانه، يك يارامتر

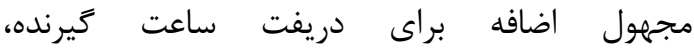

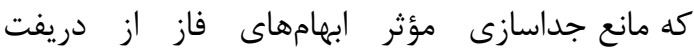

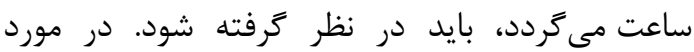
تفاضلهاى دوكانه، كه جملات ساعت حذف شرائ شدهاند، مجزا كردن ابهامها امكان يذير است [ي]. جنبهى ديخر رفع ابهام، هندسهى ماهواره مىباشـــ كـهـ مى توان از دو منظر به آن نكاه كرد. منظر اول، افـزايش

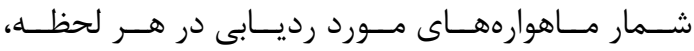

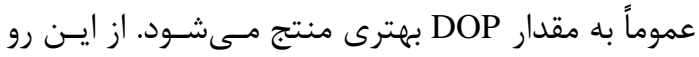

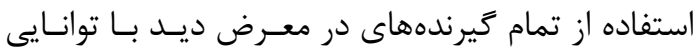

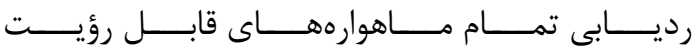

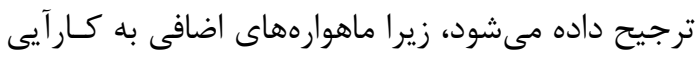

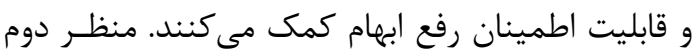
در مورد هندسه، طول زمان مورد نياز براى رفع ابهامهــا

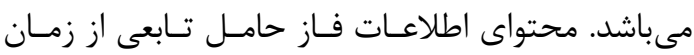
است كه مستقيماً با حر كت ماهواره همبسته است [^]ـ. خطاى جندكَانكَى مسير نيـز عامـل حسـاس و مههمى

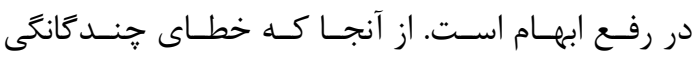

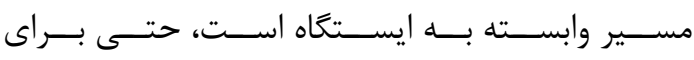
خطوط مبناى كوتاه مىتواند قابل ملاحظه باشد. رفع ابهام شامل سـه گَام اصـلى اسـت: تعريـف فضــاى جستجو ابهام، انتخاب ابهامهاى داوطلب و تعيين اعتبار

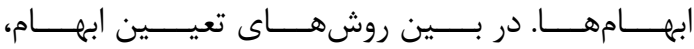

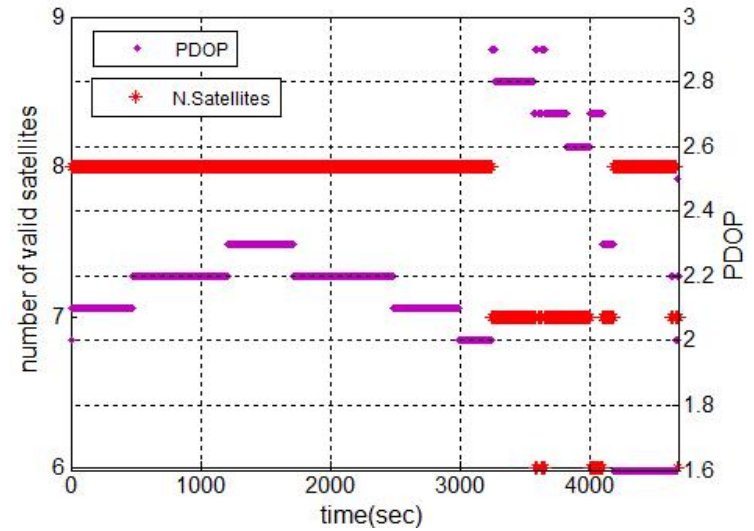

شكل V : تعداد ماهوارههاى قابل قبول براى حل موقعيت

به همراه PDOP

r-1 خطاى جـندگانگى مسير' يكى از تاثير كذارترين خطاهاى مشاهدات GNSS بـراى

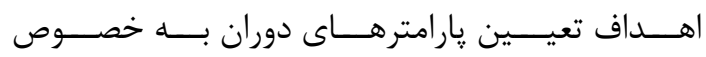
در محيطهاى آبى، خطاى جندكانكَى مسـير مسىباشـد

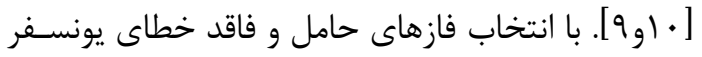

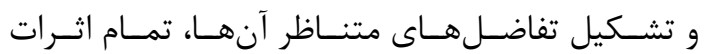

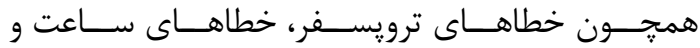

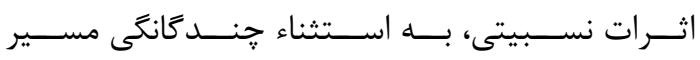

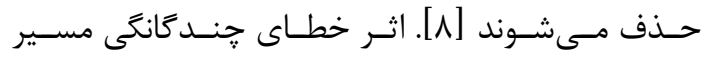
بر روى فازهاى حامـل در ايـن تحقيـق مطـابق نمـودار

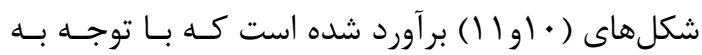
نتايج آن مىتوان متوجه شد كه خوشبختانه شرايط بــهـ

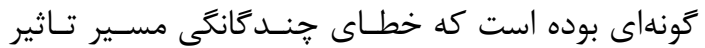
زيادى را بر دقت نهايى نتايج نداشته است.

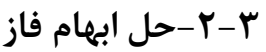

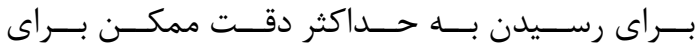

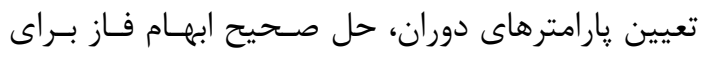

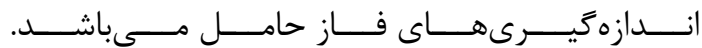

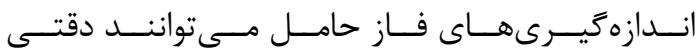
در حد ميلى متر را داشته باشند بـه شـرطى كـه ابهـام

${ }^{1}$ Multipath Error 


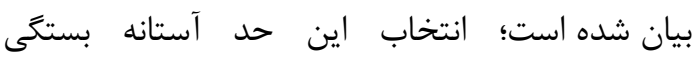

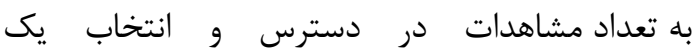
نرخ شكست دارد. در اين مقاله حد آستانهاى ثابت با داب

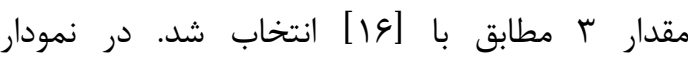
شكلهاى (^ و 9) ميزان آزمون نسبت به همراه نقاط با ابهام حل شده (fixed=1) و حل نشده (float=2)

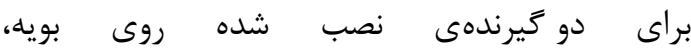

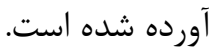

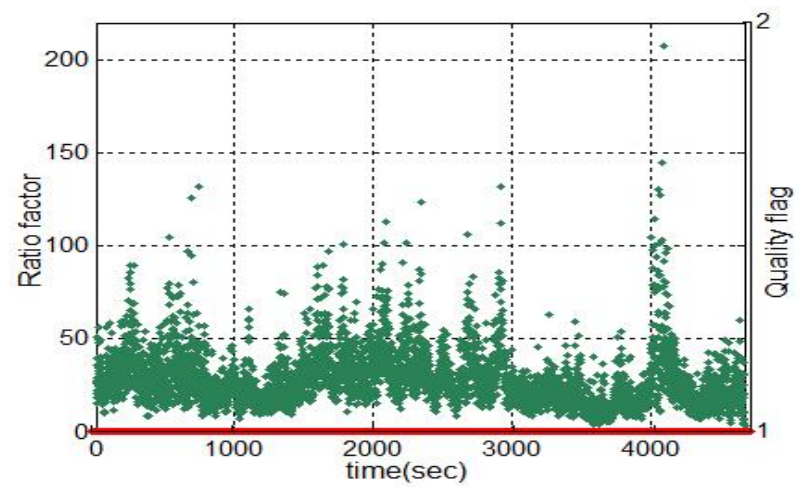

شكل 1 : مقدار آزمون نسبت (نقاط سبز) و نقاط با وضعيت حل ابهام(نقاط قرمز) دركل إيكهاى زمانى براى

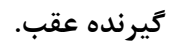

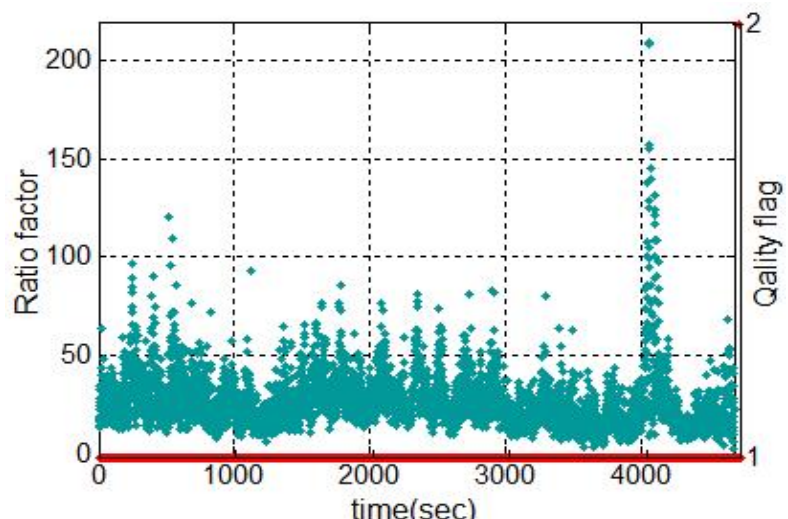

شكل 9 : مقدار آزمون نسبت (نقاط آبى) و نقاط با وضعيت (sec حل ابهام (نقاط قرمز) دركل إيكهاى زماى زمانى براى تيرنده جلو.
روش LAMBDA' از لحـاظ تئسورى و عملـى در صـدر

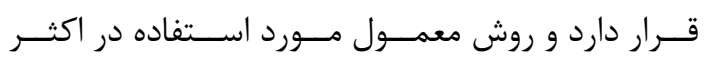

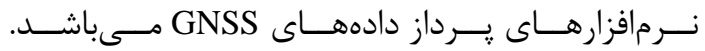
در اين روش هدف اصلى، به دست آوردن ابهامهاى عدد

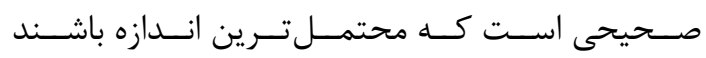

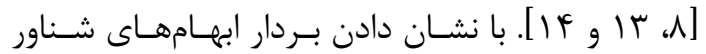
تعديل شده با Nم و بردارهاى ابهام عدد صـحيح متنـاظر

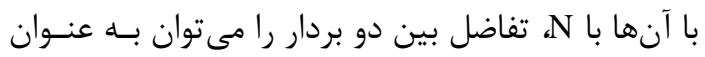

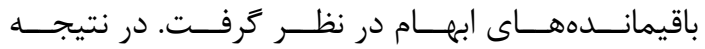

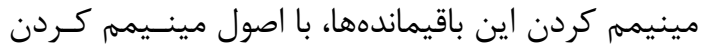
مجموع وزندار باقيماندهها، صورت مى يذيرد. با با اقتبـاس

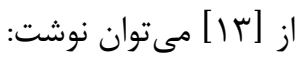

رابطه (1) $\chi^{2}(N)=(\widehat{N}-N)^{T} Q_{\widehat{N}}^{-1}(\widehat{N}-N)=$ minimum كـــهـ در آن

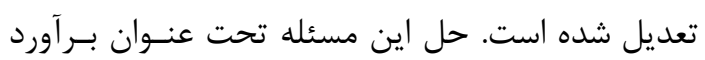
كمترين مربعات عدد صحيح ابهامها ناميده مىشود. حال براى اعتبارسنجى ابهامهاى تعيين شده مىبايست

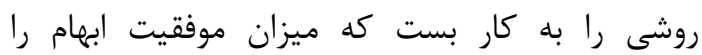

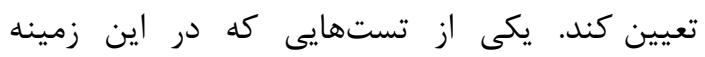
به كار كرفته مىشود تحت عنوان آزمون نسيت

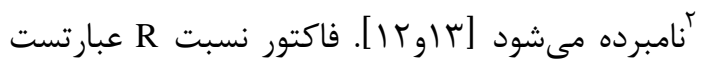

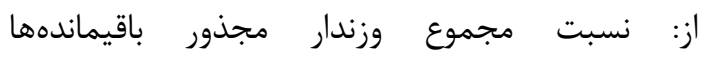

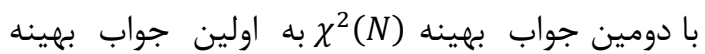
$\chi^{2}(N)$ $R=\frac{\left(\widehat{N}_{2}-N\right)^{T} Q_{\widehat{N}}^{-1}\left(\widehat{N}_{2}-N\right)}{(\widehat{N}-N)^{T} Q_{\widehat{N}}^{-1}(\widehat{N}-N)}>R_{\text {thres }} \quad$ رابطه در اين رابطه

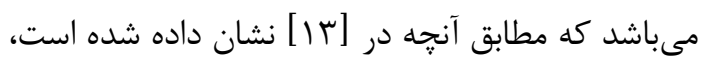

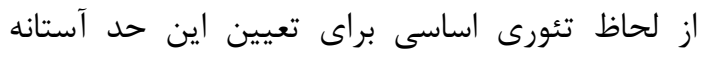

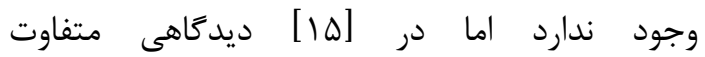

\footnotetext{
${ }^{1}$ Least-squares AMBiguity Decorrelation Adjustment ${ }^{2}$ Ratio test 

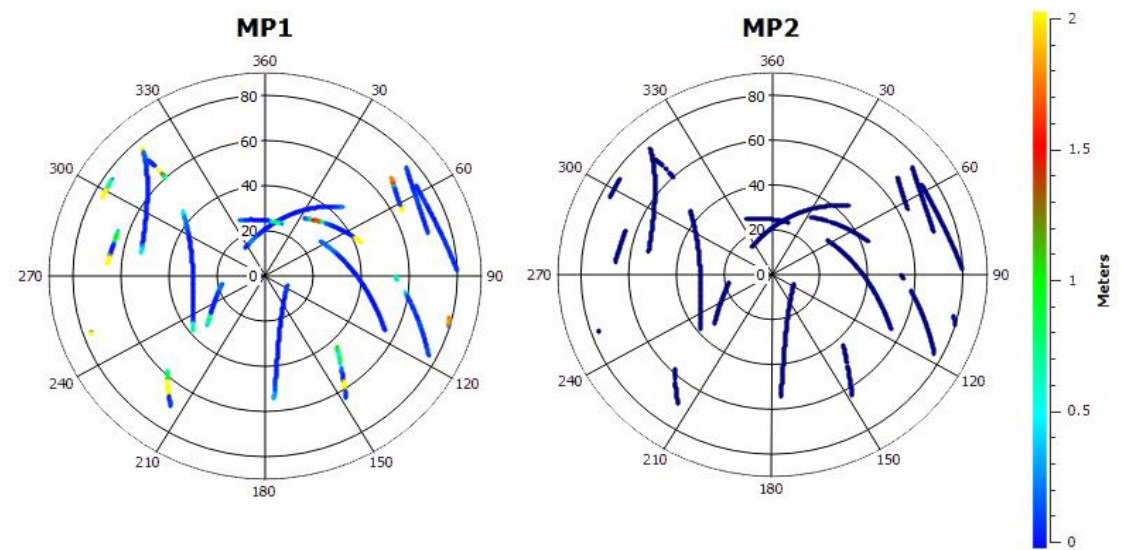

شكل • : صورت فلكى تيرنده عقب به همراه خطاى جندكانكى مسير بر آورد شده از هر ماهواره براى فر كانسهاى L1 و L2
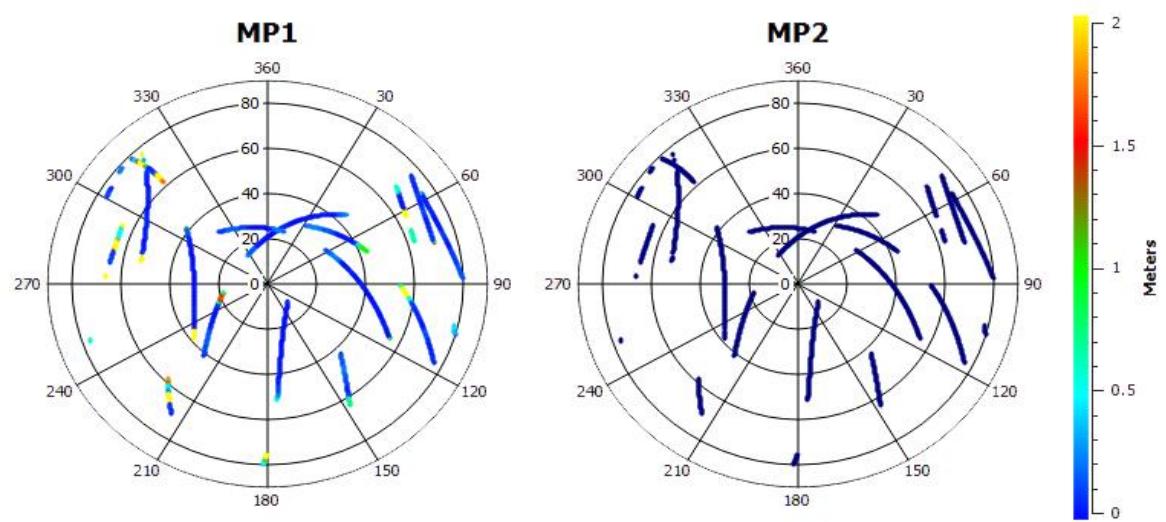

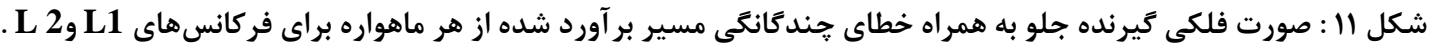
كامـل مـى كنــد) اسـت. پارامترهــاى دوران مسى توانتــد

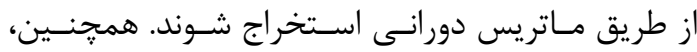

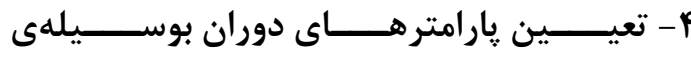
سيستم مختصات و ماتريس دوران مى توانند بـهـ عنــوان

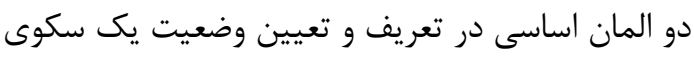
متحرك بيان شوند [9 او 11)] ץ-1 - سيستم مختصات تراز محلى و جسم مرجع سيستم مختصات تراز محلى (LL) به منوان يك سيستم مختصات مرجع به منظور اندازهيرى

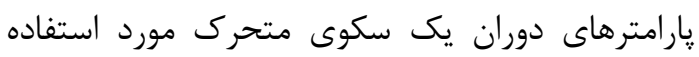

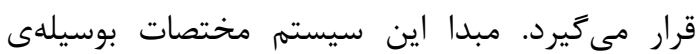

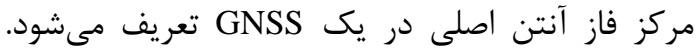

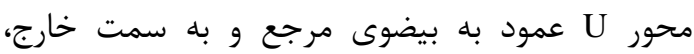

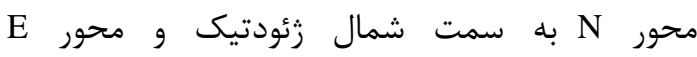

دوران يك سكوى متحرك عبارتست از توجيه سيسـتم

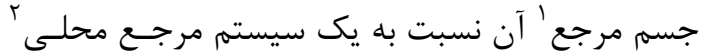

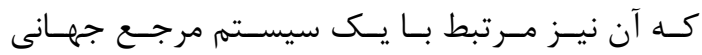

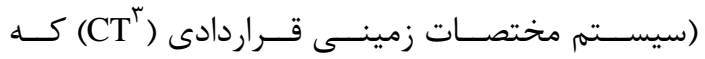

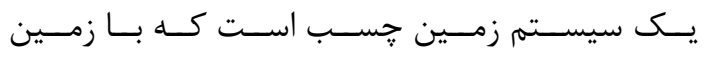

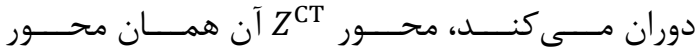

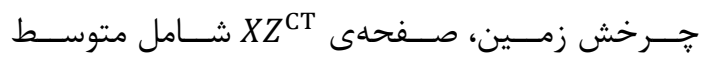
نصف النهار و محور $Y^{C T}$

${ }^{1}$ Body frame

${ }^{2}$ Local reference

${ }^{3}$ Conventional Terrestrial System 
يك سيستم دست راستى را با امتدا به شرق رابطه (9)

$r^{\mathrm{LL}}=$
$\left[\begin{array}{ccc}-\sin \lambda & \cos \lambda & 0 \\ -\cos \lambda \sin \varphi & -\sin \lambda \sin \varphi & \cos \varphi \\ \cos \lambda \cos \varphi & \sin \lambda \cos \varphi & \sin \varphi\end{array}\right] \cdot\left(\mathrm{r}^{\mathrm{CT}}-\mathrm{r}^{\mathrm{CT}_{0}}\right)$ مى توان معادله (9) را نيز بدين صورت نوشت: $r^{\mathrm{LL}}=\mathrm{R}_{\mathrm{CT}}^{\mathrm{LL}} \cdot\left(\mathrm{r}^{\mathrm{CT}}-\mathrm{r}^{\mathrm{CT}}{ }_{0}\right)=\mathrm{R}_{\mathrm{CT}}^{\mathrm{LL}} \cdot \Delta \mathrm{r}^{\mathrm{CT}} \quad(\mathrm{V})$

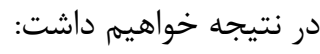

(^) رابطه () ()

$\mathrm{R}_{\mathrm{CT}}^{\mathrm{LL}}=\left[\begin{array}{ccc}-\sin \lambda & \cos \lambda & 0 \\ -\cos \lambda \sin \varphi & -\sin \lambda \sin \varphi & \cos \varphi \\ \cos \lambda \cos \varphi & \sin \lambda \cos \varphi & \sin \varphi\end{array}\right]$

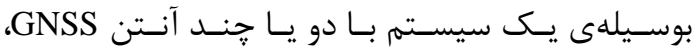

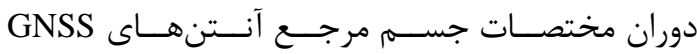

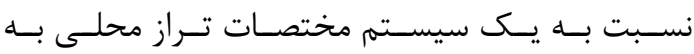

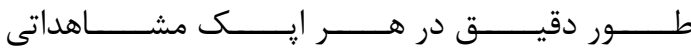
قابل محاسبه مى باشد.

بــراى توصــيف ارتبــاط ميــان سيسـتم مختصــات

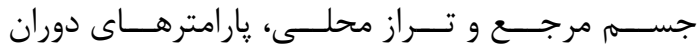

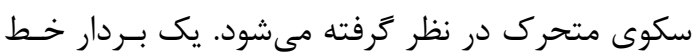

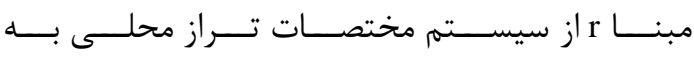

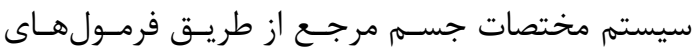

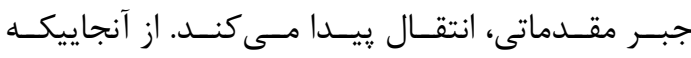
سيستم مختصات تراز محلى و جسم مرجـع در مبــاندا و مقياسى همانند سهيم مى باشند، ارتباط ميان آنها برابـر

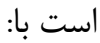
$r^{\mathrm{BF}}=\mathrm{R}_{\mathrm{LL}}^{\mathrm{BF}} \cdot \mathrm{r}^{\mathrm{LL}}$

(9) (9) كه rBF بردار خط مبنـا بيـان شـده در سيسـتم جسـم

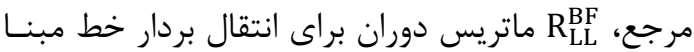

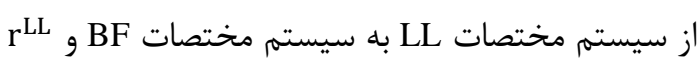

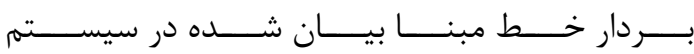

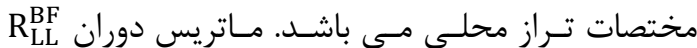

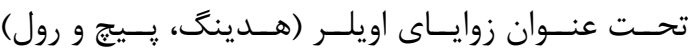
توصــيف مــــــــود. روش معمــــول بـــراى انتقـــال
تكميل مى كند [ ل اواور].

بردار خط مبنا از يكى آنتن اصلى بـهـ يـك آنـتن ثانويـهـ بوسيلهى GNSS در سيستم WGS84 تعيين مىشـود.

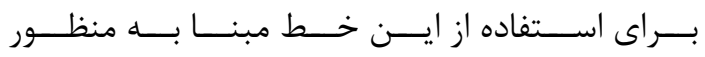
تعيين بارامترهـاى دوران، لازم اسـت كـهـ بـهـ سيسـته

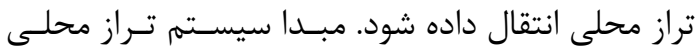

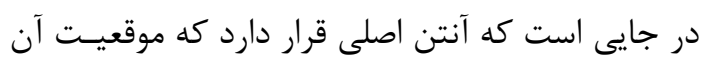
معمولا بوسيلهى اندازهزيرىهاى شبه فاصـله

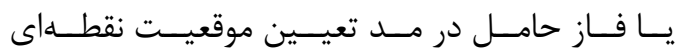

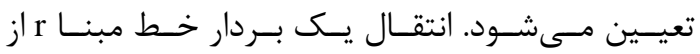

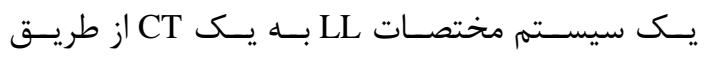
روايط زير صورت مى يذيرد: $\mathrm{r}^{\mathrm{CT}}=\mathrm{R}_{\mathrm{LL}}^{\mathrm{CT}} \cdot \mathrm{r}^{\mathrm{LL}}+\mathrm{r}^{\mathrm{CT}} \quad$ (ए)

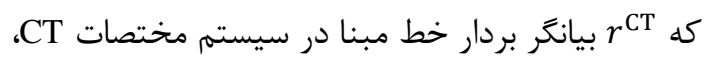

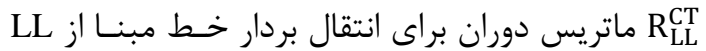

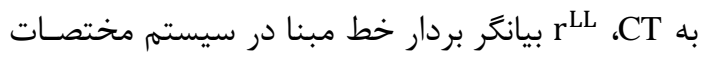

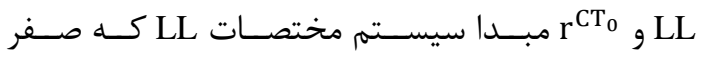
نشاندهنده ى اين است كه در سيسـتم مختصـات مختصات

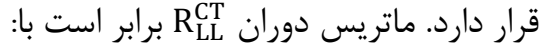
$\mathrm{R}_{\mathrm{LL}}^{\mathrm{CT}}=R_{3}\left(-\lambda-\frac{\pi}{2}\right) \cdot \mathrm{R}_{1}\left(\varphi-\frac{\pi}{2}\right) \quad$ (F) رابطه

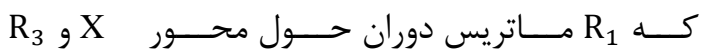

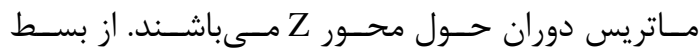
معادلهى بالا خواهيم داشت:

رابطه (a)

$\mathrm{R}_{\mathrm{LL}}^{\mathrm{CT}}=\left[\begin{array}{ccc}-\sin \lambda & -\cos \lambda \sin \varphi & \cos \lambda \cos \varphi \\ \cos \lambda & -\sin \lambda \sin \varphi & \sin \lambda \cos \varphi \\ 0 & \cos \varphi & \sin \varphi\end{array}\right]$

همجنين ماتريس دوران براى انتقال يك بردار خط مبنا

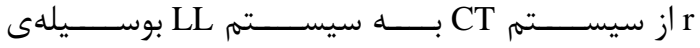

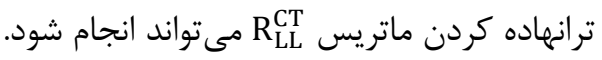




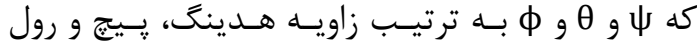
جسم متحرك مى باشند. با استفاده خاصيت ارتو كونـالى

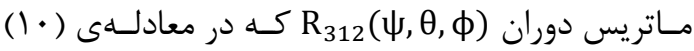

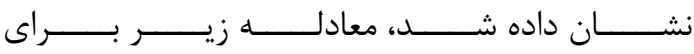
محاسبهى زواياى هدينَ مورد استفاده قرار مى گيرد: $\psi=\arctan \frac{\Delta E}{\Delta N}$

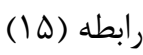

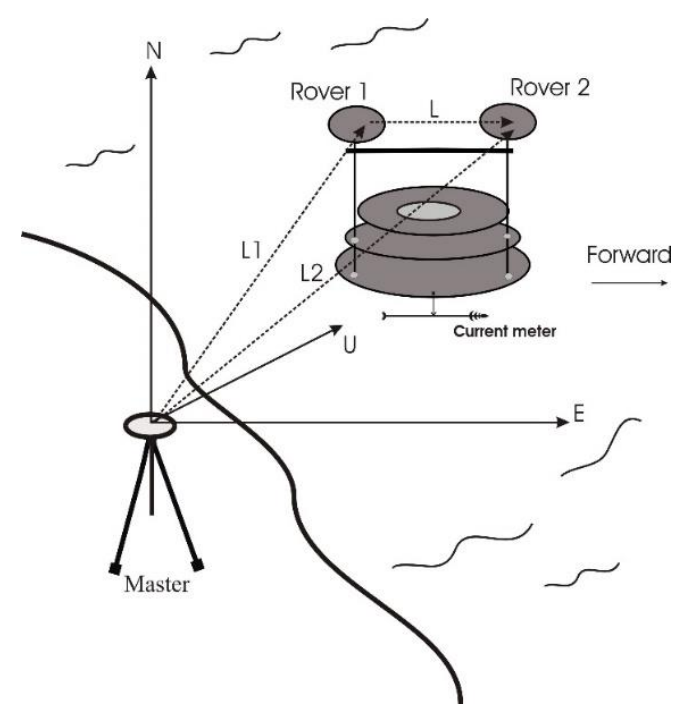

شكل r ا : اساس سيستم مختصات تراز محلى

كه

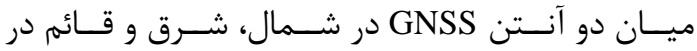

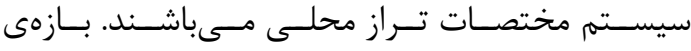

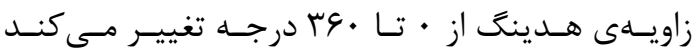
$[\wedge,|\vee,| \wedge]$

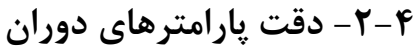
دقت زاوياى هدينَ كه از طريق معـادلات بـهـ صـورت

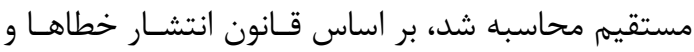

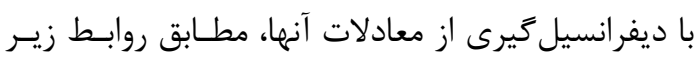
قابل محاسبه مىباشد .

با توجـه بـه اينكـه: خطــاى موقعيـت نقــاط $\left(\sigma_{e}, \sigma_{\mathrm{n}}, \sigma_{\mathrm{u}}\right)$ g $\left(e_{1}, n_{1}, u_{1}\right)$

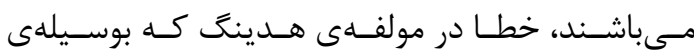

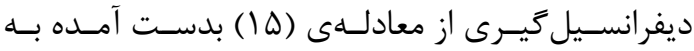

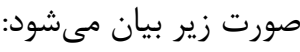

از سيستم مختصات تـراز محلـى بــه سـيتم مختصـات

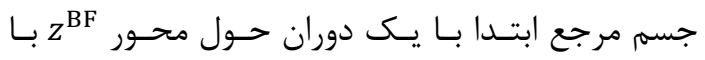

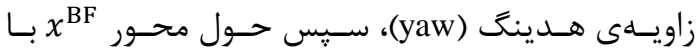

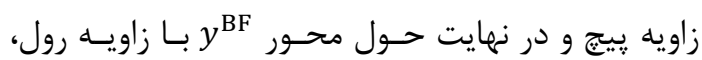
مطابق با معادلات زير صورت مى خيرد: رابطه (•) (1)

$R_{\mathrm{LL}}^{\mathrm{BF}}=\mathrm{R}_{2}(\phi) \mathrm{R}_{1}(\theta) \mathrm{R}_{3}(\psi)=\mathrm{R}_{312}(\psi, \theta, \phi)$

$R_{2}(\phi)=\left[\begin{array}{ccc}\cos \phi & 0 & \sin \phi \\ 0 & 1 & 0 \\ -\sin \phi & 0 & \cos \phi\end{array}\right] \quad$ (1) $R_{1}(\theta)=\left[\begin{array}{ccc}1 & 0 & 0 \\ 0 & \cos \theta & -\sin \theta \\ 0 & \sin \theta & \cos \theta\end{array}\right] \quad$ (Ir) $R_{3}(\psi)=\left[\begin{array}{ccc}\cos \psi & -\sin \psi & 0 \\ \sin \psi & \cos \psi & 0 \\ 0 & 0 & 1\end{array}\right] \quad$ (1

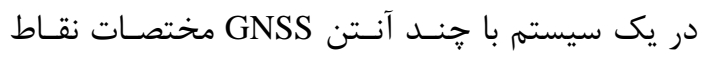

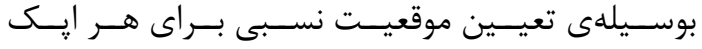

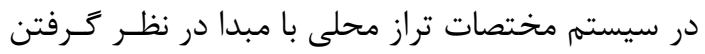

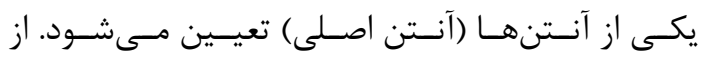

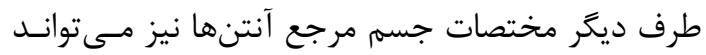

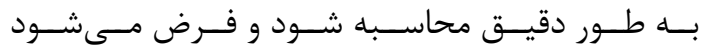

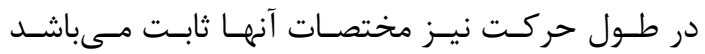

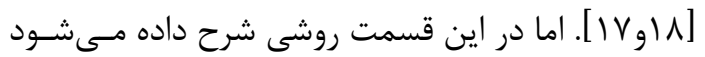

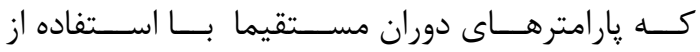
مختصات تراز محلى آنتنها و بدون نيـاز بـهـ مختصـات

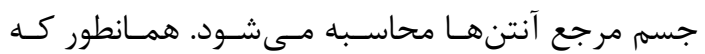
در شكل (r) نشان داده شده است، ايستخاه ثابـت بـهـ

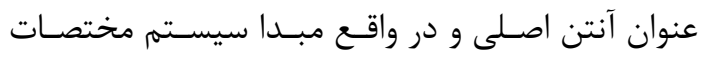

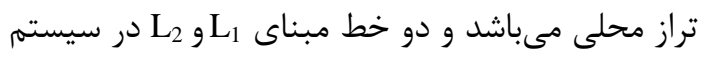

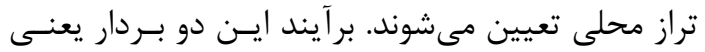
بردار L، بردارى است در سيستم مختصات جسم مرجع

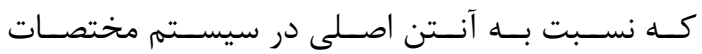
تراز محلى با ماتريس دوران زير، دوران مى كند: $\mathrm{L}^{\mathrm{BF}}=\mathrm{R}_{312}(\psi, \theta, \phi) \cdot \mathrm{L}^{\mathrm{LL}}$ رابطه (If) 
$\sigma_{\Psi}=\sqrt{\left(\frac{\Delta N}{\Delta E^{2}+\Delta N^{2}}\right)^{2}\left(\sigma_{\mathrm{e} 1}^{2}+\sigma_{\mathrm{e} 2}^{2}\right)+\left(\frac{\Delta E}{\Delta E^{2}+\Delta N^{2}}\right)^{2}\left(\sigma_{\mathrm{n} 1}{ }^{2}+\sigma_{\mathrm{n} 2}{ }^{2}\right)}$

رابطه (19)

كه در اين رابطه $\theta$ زاويـهـ يـيـيج بويسه بـوده و بـهـــورت

حال با توجه به داشتن يـك خـط مبنــا ميـان دو آنـتن

$\theta=\arctan \frac{\Delta U}{\sqrt{\Delta \mathrm{E}^{2}+\Delta \mathrm{N}^{2}}}$

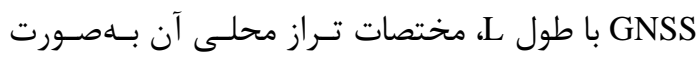

بـا صــرفنظر كـردن از همبســتخى ميــان مولفـهـهـاى

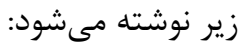

مختصات، انحراف معيار يارامتر هدينگ برابر است با:

$\left[\begin{array}{c}\Delta \mathrm{E} \\ \Delta \mathrm{N} \\ \Delta \mathrm{U}\end{array}\right]=\left[\begin{array}{c}\mathrm{L} \cos \theta \sin \psi \\ \mathrm{L} \cos \theta \cos \psi \\ \mathrm{L} \sin \theta\end{array}\right]$

رابطه (IV)

رابطه (1N)

$\sigma_{\Psi}=\sqrt{\left(\frac{\mathrm{L} \cos \theta \cos \psi}{\mathrm{L}^{2} \cos ^{2} \theta \sin ^{2} \psi+\mathrm{L}^{2} \cos ^{2} \theta \cos ^{2} \psi}\right)^{2}\left(\sigma_{\mathrm{e} 1}{ }^{2}+\sigma_{\mathrm{e} 2}{ }^{2}\right)+\left(\frac{\mathrm{L} \cos \theta \sin \psi}{\mathrm{L}^{2} \cos ^{2} \theta \sin ^{2} \psi+\mathrm{L}^{2} \cos ^{2} \theta \cos ^{2} \psi}\right)^{2}\left(\sigma_{\mathrm{n} 1}{ }^{2}+\sigma_{\mathrm{n} 2}{ }^{2}\right)}$

$\sigma_{\Psi}=\frac{\sqrt{\cos ^{2} \theta\left(\sigma_{\mathrm{e} 1}^{2}+\sigma_{\mathrm{e} 2}{ }^{2}\right)+\sin ^{2} \psi\left(\sigma_{\mathrm{n} 1}{ }^{2}+\sigma_{\mathrm{n} 2}{ }^{2}\right)}}{\mathrm{L} \cos \theta}$

رابطه (19)

بـر روى بويسه و ميـزان محاسـبـه شـدهى آن از طريـق دادهاى موقعيت مىباشد.

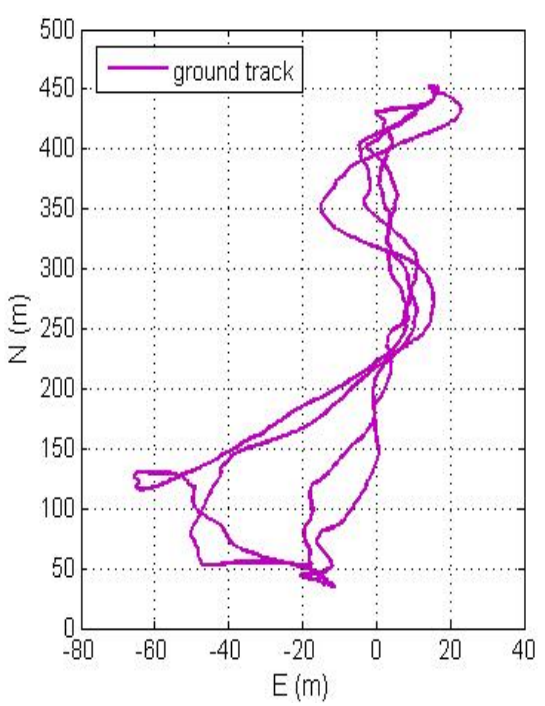

شكل سا : مسير طى شدهى بويه بر روى آب
همانطور كه واضح است، زمانى كه دقت تعيين موقعيت

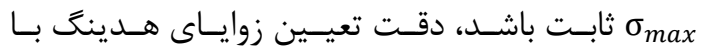
نسـب معكـوس خـــ مبنــا L رابطـهـى مســتقيم دارد.

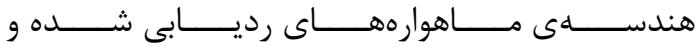
نحوهى ييكربندى آنتن هاى GNSS در مسـائل مربـوط به تعيين يارامترهاى دوران يك سكوى متحرى بـ بر روى

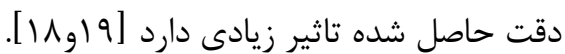

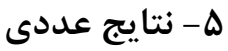

با استفاده از دادههاى موقعيت مكانى بويــهـ بــر روى آب كه طى مدت زمـانى مشـخص و در مسـيرهاى رفت و

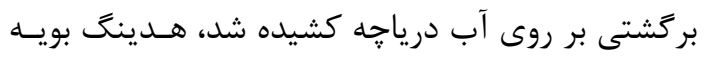
بــا دقـت مناســبى محاســبه شــد. در شـكل (II) مسير طى شدهى بويسه بـر روى آب مشـاهده مسى شــود

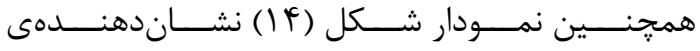
اختلاف طول خــط واصـل ميـان دو آنـتن نصسب شـده 


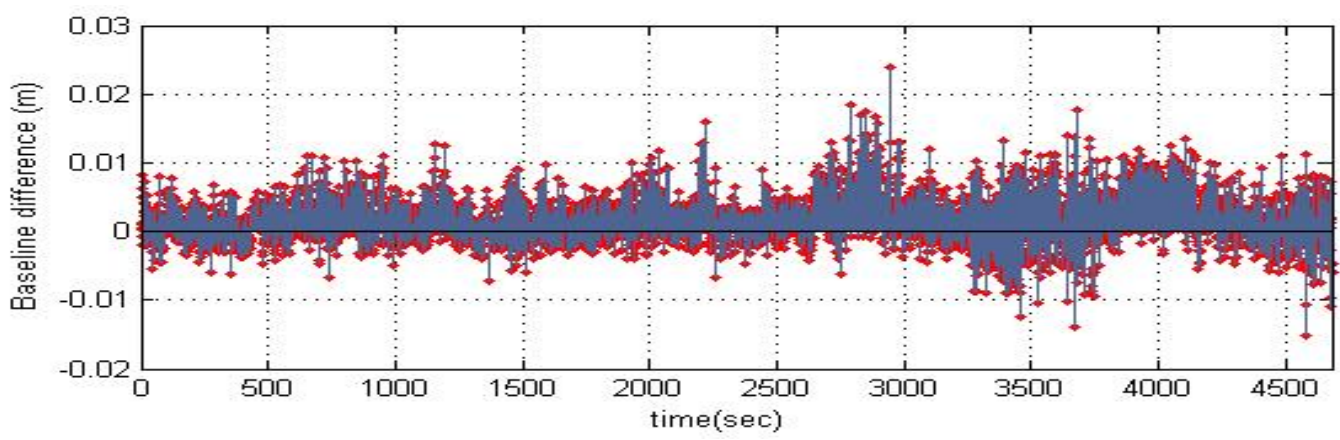

شكل If : خطاى خط مبنا L (متر)

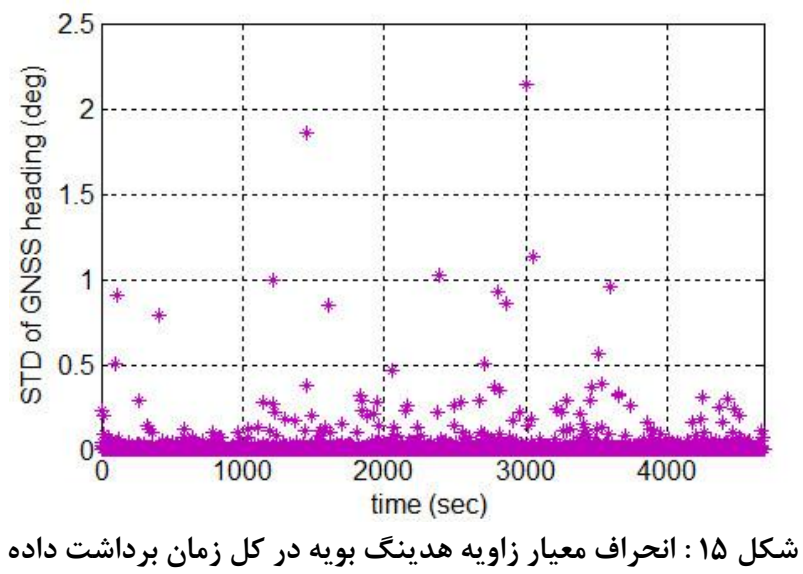

جدول I : يارامترهاى محاسباتى بويه

\begin{tabular}{|c|c|}
\hline مقادير & يارامتر محاسباتى \\
\hline | | | | | • متر & متوسط خطاى خط مبنا (L) \\
\hline س & خطاى خط مبنا RMSE \\
\hline 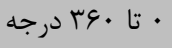 & رنج زاويه هدينگ اندازهخيرى شده \\
\hline ( F F/TVG. & انحراف معيار مولفه هدينَ \\
\hline
\end{tabular}

مورد استفاده قرار كرفت. همجنين با توجه بــه جـدايى

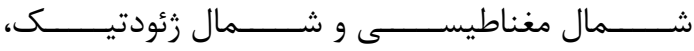

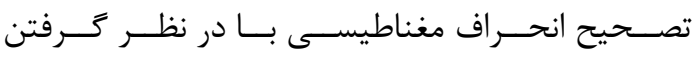

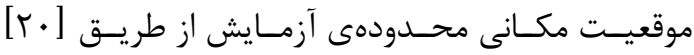

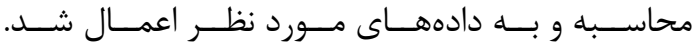
نمودار شكل (1) هدينَ حاصل از محاسبات دادههاى

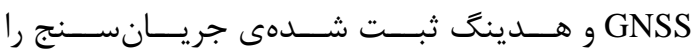

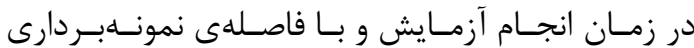

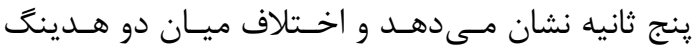

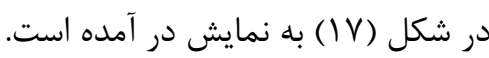

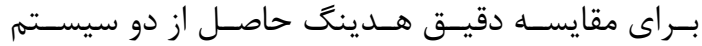

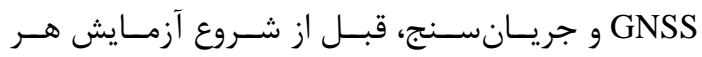

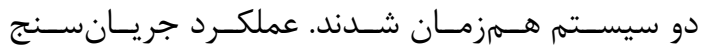

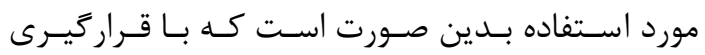
در مقابل جريان آب، در كمينهى نرخ نمونهبردارى خود

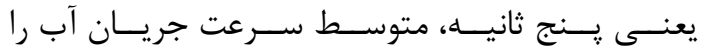
در اين زمان به عنوان يارامتر سرعت و در ثانيـه يــنجم

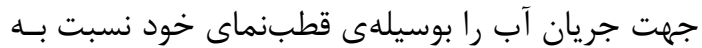

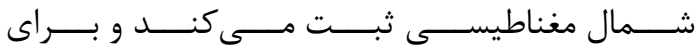
مقايسهى هدينَ حاصل از GNSS با هدينَ حاصل از جريانسنج نيز هدينَ بويسه در هـر يــنج ثانيسه يكبـار 

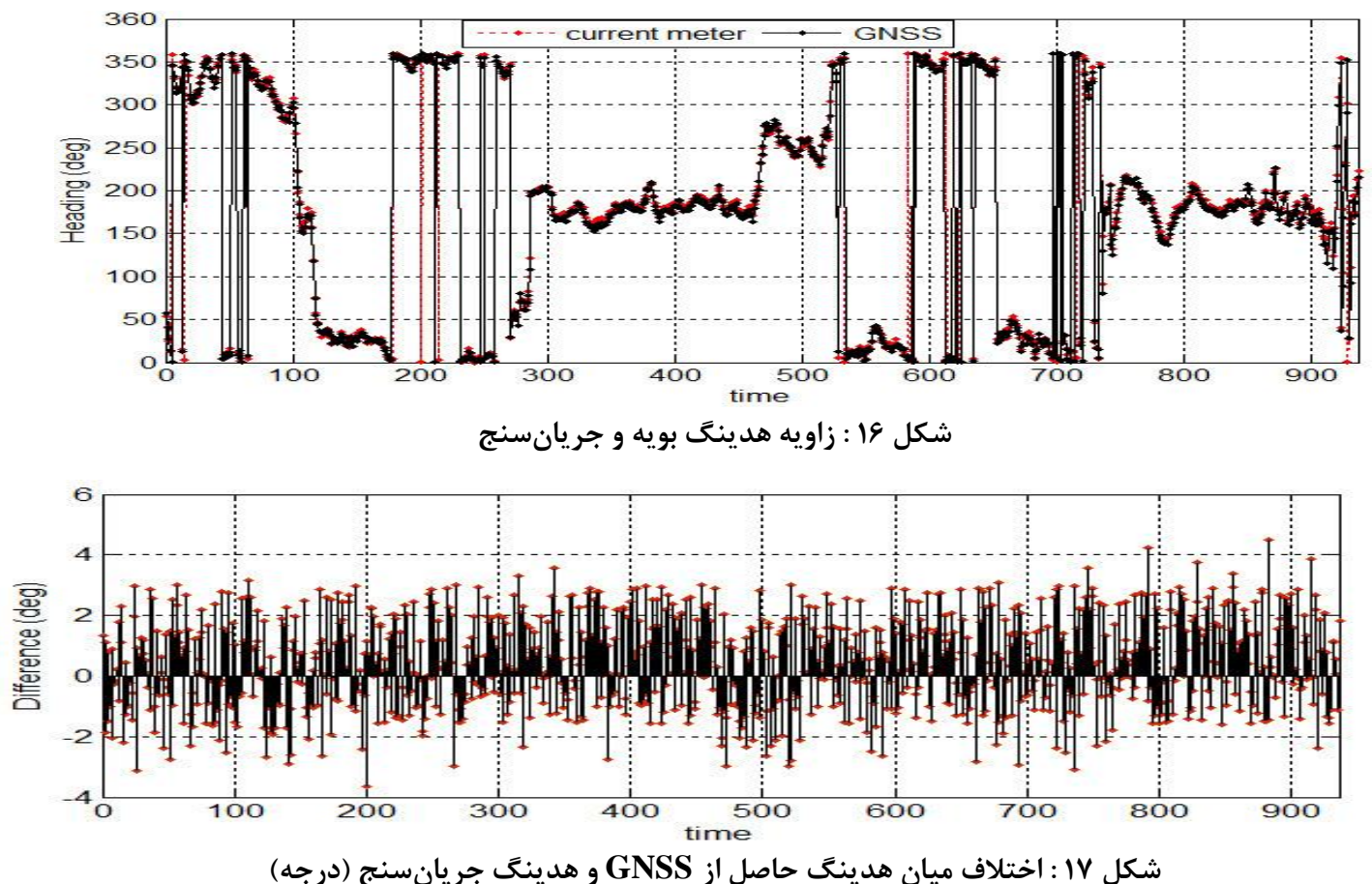

تحـت تـاثير قـرار زيــرد، اخـتلاف محسوسـى نبـوده و

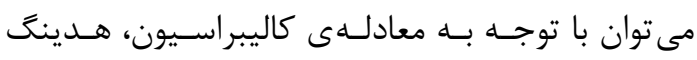

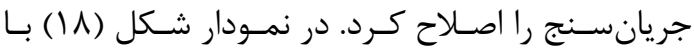

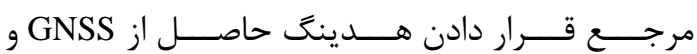

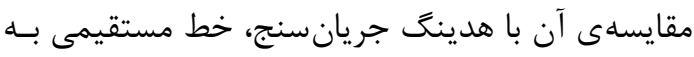
دادهها فيت و معادله خطى مطابق آن آورده شده است.
در جدول (Y) يارامترهاى آمارى مربـوط بـه مقايسـهى

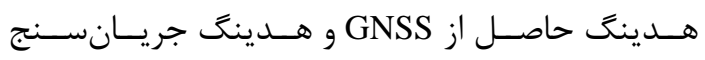
آورده شده است. مشاهده مى شود كه متوسـط اخــتلاف

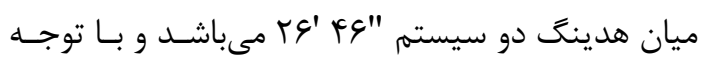

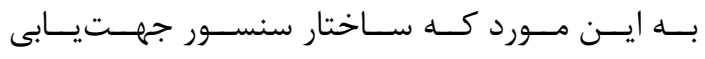

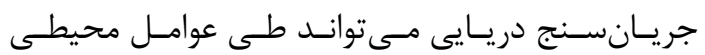

جدول Y : مقايسهى هدينَ جريانسنج با هدينَ GNSS

\begin{tabular}{|c|c|}
\hline مقادير & هارامتر محاسباتى \\
\hline T\&' FE" & متوسط اختلاف \\
\hline$\mu^{\circ} r \Lambda^{\prime} r \Delta^{\prime \prime}$ & ماكزيمم اختلاف \\
\hline$q^{\prime \prime}$ & مينيم اختلاف \\
\hline $1^{\circ}$ rq" $^{\prime \prime}$ & انحر اف معيار \\
\hline $1^{\circ} r r^{\prime} \Delta \varphi^{\prime \prime}$ & جذر خطاى مربعى متوسط \\
\hline
\end{tabular}




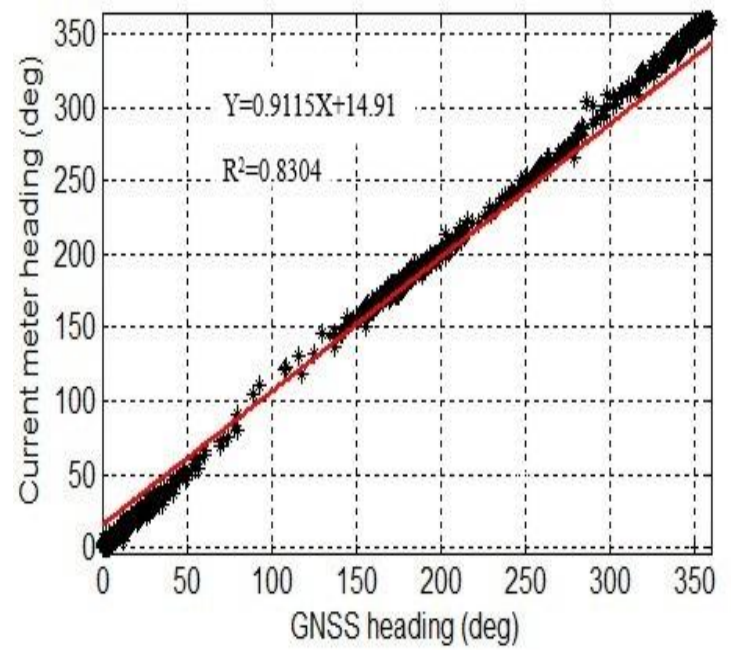

شكل 11 : مقايسهى هدينَ جريانسنج با هدينَ بويه

به امكانات موجود ساخته شد كه مى بوان شناورى بهتـر

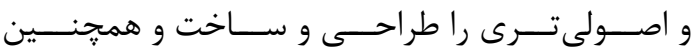

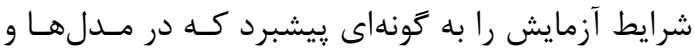

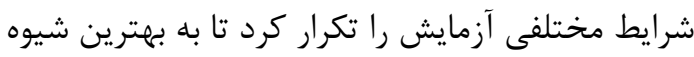

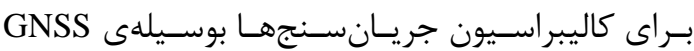

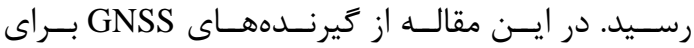
بررسى قطبنماى جريانسنج استفاده شد كه مى تـوان

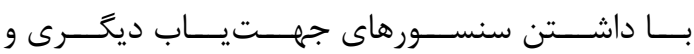
مرتبط كردن آنها باهم، نتايج دقيقترى نيز كسب كرد. روش مورد نظر مى تواند سنسور سرعتسنجى دسـتخاه

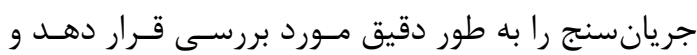

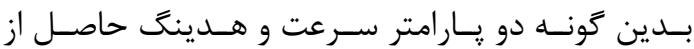

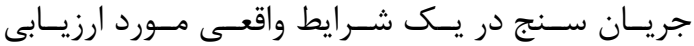

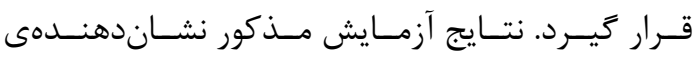

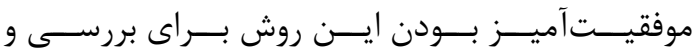
كاليبراسيون جريانسنجهـاى دريـايى از نـوع بروانـهاى

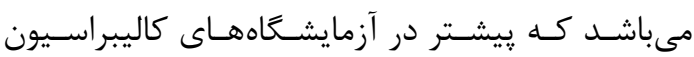

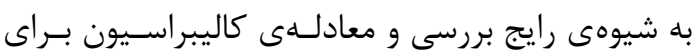

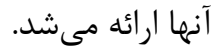

$$
\text { تشكر و قدردانى }
$$

بدينوسيله از سـازمان نقشـهــردارى كشـور بــه جهـت

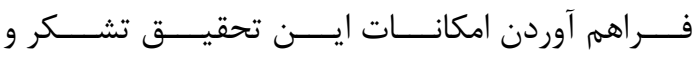

9- نتيجه كيرى و ييشنهادات

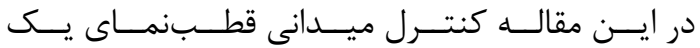

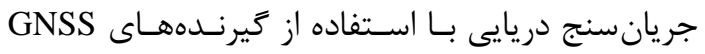
مورد بررسى قرار كرفت. زاويه هدينخ بويسه بـه عنــوان

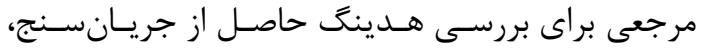

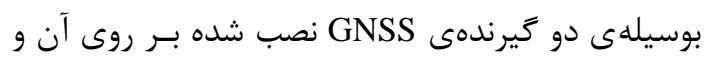

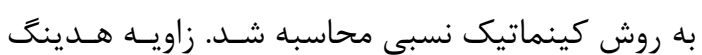

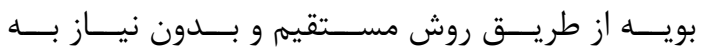

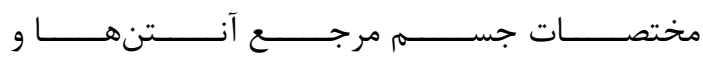
با داشتن مختصات آنتنها در سيسـتم مختصـات تـراز

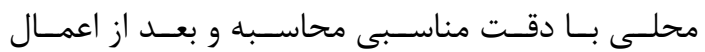
تصحيحات (انحراف مغناطيسى) با هدينگ ثبت شـدهى قطبنماى مغناطيسى جريانسنج دريايى مقايسـه شـد.

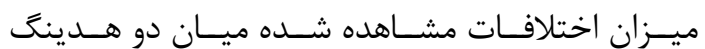

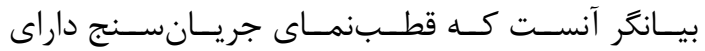

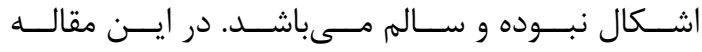

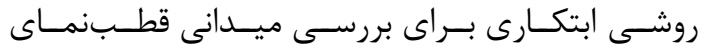

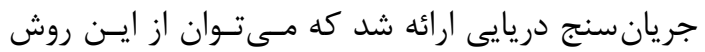

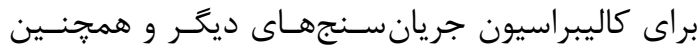

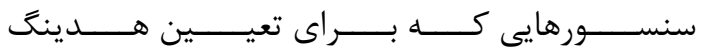

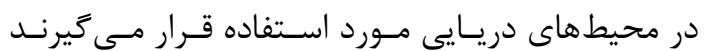

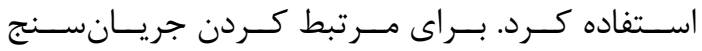

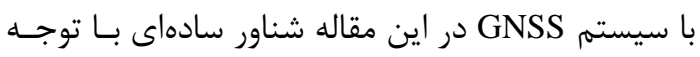




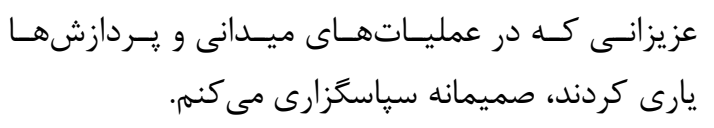

[1] Gwyn Griffiths, "Using 3Df GPS heading for improving underway ADCP data." American meteorological society, Vol.11, 1135-1143, 1994.

[2] Raymond pollard, Jane read, "A method for calibrating shipmounted acoustic Doppler profilers and the limitation of gyro compasses" Journal of atmospheric and ocean technology, Vol. 6, NO. 6, 1989.

[3] SIMÓN RUIZ, JORDI FONT, GWYN GRIFFITHS, ARTURO CASTELLÓN, "Estimation of heading gyrocompass error using a GPS 3DF system: Impact on ADCP measurements", SCI. MAR., 66 (4): 347$354,2002$.

[4] CLIFFORD L. TRUMP, GEORGE O. MARMORINO, "Calibrating a Gyrocompass Using ADCP and DGPS Data.", JOURNAL OF ATMOSPHERIC AND OCEANIC TECHNOLOGY VOLUME 14, 1997.

[5] Patrick Henkel, philipp berthold, jane jean kiam, "Calibration of magnetic field sensors with tow mass-market GNSS receivers." IEEE WPNC, 2014.

[6] J. Crassidis, K. L. Lai and R. Haman, "Realtime attitude-independent three axis magnetometer calibration." J. of Guidance, Control, and Dynamics, Vol. 28. NO. 1, pp. 115-120, 2005.

[7] Rolf Dach, Urs Hugentobler, Pierre Fridez, Michael Meindl, "User manual of the Bernese GPS Software Version 5.0", Astronomical Institute, University of Bern, 2007.

[8] Hofman-Wellenhof, Lichtenegger, Wasle, GNSS-global navigation satellite systems: GPS, GLONASS, Galileo and more,
قدردانى مى كنم. همجنين از جناب دكتر على سلطانيور

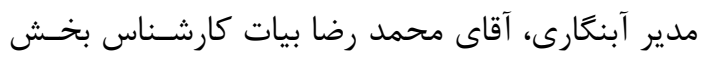

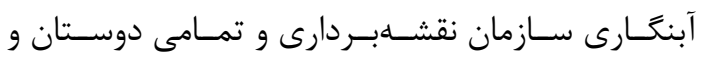

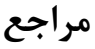

Springer, Verlag Wien, 2008.

[9] K. Yedukondalu, A. D. Sarma, and V. Satya Srinivas, "ESTIMATION AND MITIGATION OF GPS MULTIPATH INTERFERENCE USING ADAPTIVE FILTERING”, Progress In Electromagnetics Research M, Vol. 21, 133, 2011

[10] J.K. Ray. M.E. Cannon, "Characterization of GPS Carrier Phase Multipath" Presented at ION NTM-99, San Diego, January 25-27, 1999

[11] Gabriele Giorgi and Peter J. G. Teunissen, "GNSS Carrier Phase-Based Attitude Determination", Recent Advances in Aircraft Technology, 2012.

[12]P. J. Buis, "GNSS Kinematic Relative Positioning for Spacecraft: Data Analysis of a Dynamic Testbed." Delft University of Technology, the Netherlands, 2008.

[13] Teunissen, P.J.G., Verhagen, S, "On the Foundation of the Popular Ratio Test for GNSS Ambiguity Resolution" ION GNSS2004, Long Beach, CA, US, 2004.

[14] Gabriele Giorgi, Peter J. G. Teunissen, "Carrier Phase GNSS Attitude Determination with the Multivariate Constrained LAMBDA Method", IEEEAC Paper, 2010.

[15] Teunissen, P.J.G.: Verhagen, S, "On GNSS Ambiguity Acceptance Tests", International Global Navigation Satellite Systems Symposium, The University of New South, 2007.

[16] Wei, M.: Schwarz, K.P, "Fast Ambiguity Resolution using an Integer Nonlinear Programming Method" ION GPS1995, Palm Springs CA, US, 1995. 
كاليبر اسيون قطب نماى جريان سنج دريايى با استفاده از ....

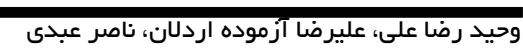

[17] Gang Lu, "Development of a GPS MultiAntenn System for Attitude Determination" PhD Thesis, DEPARTMENT OF GEOMATICS ENGINEERING CALGARY, ALBERT, 1995.

[18] JiunHan Keong, "Determining Heading and Pitch Using a Single Difference GPS/GLONASS approach" master of science Thesis. CALGARY, ALBERTA,
1999.

[19] M.vinnins, L.D. Gllop, "GPS heading determination using short antenna baselines", Defense research establishment Ottawa, technical note 98-001, 1997.

[20] http://www.ngdc.noaa.gov/geomag-web/ 


\title{
Marine current meter compass calibration Using relative kinematic positioning
}

Vahid Rezaali*1, Alireza Azmoode Ardalan ${ }^{2}$, Naser Abdi $^{3}$

\footnotetext{
1- M.Sc student of hydrography in School of Surveying and Geospatial Eng., Faculty of Engineering, University of Tehran

2- Professor in School of Surveying and Geospatial Eng., Faculty of Engineering, University of Tehran

3- PhD student of geodesy in School of Surveying and Geospatial Eng., Faculty of Engineering, University of Tehran
}

\begin{abstract}
Highly accurate parameters for velocity and direction of marine current are of utmost importance in marine studies. To achieve this, accurate and calibrated current meters should be used. The direction parameters or "heading" resulted from marine current meter is measured by the aid of a compass mounted on the device. This, as well as the velocity parameter should be properly evaluated and margin of error calculated. In this paper GNSS receivers have been utilized to calibrate the compass on a marine current meter. In this method, two GNSS receivers have been installed on a buoy and then connected to a current meter. The buoy then has been pulled on a lake in a specified direction. In this method two GNSS receivers mounted on buoy using carrier phase observations have been positioned relative to a reference station and by defining a local level coordinate with the reference station as the origin, from rotation the baseline created between the two receivers to this station, heading angle has been calculated. To verify the accuracy of the calculated heading angle, criterion such as satellite geometry, solving phase ambiguity and multipath error in kinematic positioning is evaluated. Heading angles of the buoy was determined with a standard deviation 48.2760" and were compared with the headings of current meter that mean difference between heading from compass current meter and GNSS heading 26'46" is determined and calibration equation is presented for current meter compass.
\end{abstract}

Key words: heading angle, GNSS, relative kinematic, marine current meter, current meter calibration

Correspondence Address: School of Surveying and Geospatial Eng., Faculty of Engineering, University of Tehran, Tehran, Iran. Tel: +989357720877

Email: geo1.vra@gmail.com 